\title{
Role of Moderate Hypothermia and Antegrade Cerebral Perfusion during Repair of Type A Aortic Dissection
}

\author{
Sotiris C. Stamou, MD ${ }^{1} \quad$ Michael A. McHugh, MD $\quad$ Brian D. Conway, MD ${ }^{2}$ Marcos Nores, MD ${ }^{1}$ \\ ${ }^{1}$ Department of Cardiovascular Surgery, JFK Medical Center, Atlantis, \\ Florida \\ 2 University of lowa Hospitals and Clinics, University of lowa, \\ lowa City, lowa \\ Address for correspondence Sotiris C. Stamou, MD, PhD, Department \\ of Cardiothoracic Surgery, JFK Medical Center, 180 JFK Drive, Suite \\ 320, Atlantis, FL 33462 (e-mail: sotiris.stamou@hotmail.com). \\ Int J Angiol 2018;27:190-195.
}

\begin{abstract}
Keywords

- aortic dissection

- hypothermia

- outcomes

- mortality

- morbidity

- renal failure

- cardiac surgery

The goal of this study was to compare early postoperative outcomes and actuarial survival between patients who underwent repair of acute type $A$ aortic dissection with deep or moderate hypothermia.

A total of 132 consecutive patients from a single academic medical center underwent repair of acute type A aortic dissection between January 2000 and June 2014. Of those, 105 patients were repaired under deep hypothermia $\left(<24 \mathrm{C}^{\circ}\right)$, while 27 patients were repaired under moderate hypothermia $\left(\geq 24 \mathrm{C}^{\circ}\right)$. Median ages were 62 years (range: 27-86) and 59 years (range: 35-83) for patients repaired under deep hypothermia compared with patients repaired under moderate hypothermia, respectively $(p=0.451)$. Major morbidity, operative mortality, and 10 -year actuarial survival were compared between groups.

Operative mortality was 17.1 and $7.4 \%$ in the deep and moderate hypothermia groups, respectively $(p=0.208)$. Incidence of permanent stroke was $12.4 \%$ in the deep hypothermic circulatory arrest group and $0 \%$ in the moderate hypothermia group $(p=0.054)$. Actuarial 5 - and 10-year survival demonstrated a trend for lower long-term mortality with moderate hypothermia compared with deep hypothermia (69\% 5-year and 54\% 10-year for deep hypothermia vs. 79\% 5-year and 10-year for moderate hypothermia, log-rank $p=0.161$ ).

Moderate hypothermia is a safe and efficient alternative to deep hypothermia and may have protective benefits. Stroke rate was lower with moderate hypothermia.
\end{abstract}

Acute type A aortic dissection is a severe condition requiring immediate surgical intervention and is associated with high rates of morbidity and mortality. Despite improvements in accurate early diagnosis, cerebral protection methods, and prompt repair, recent studies continue to report postoperative mortality rates reaching 15 to $26 \% .^{1-5}$ The deep hypothermic arrest technique of distal anastomosis in aortic surgery disrupts blood flow to the brain and other vital organs, leaving them vulnerable to injury. Morbidity and mortality caused by brain-related complications during aor- tic arch surgery are the most prevalent, with cerebral protection by hypothermic circulatory arrest (HCA) or cerebral perfusion. ${ }^{6-8}$ Nevertheless, literature directly addressing temperature selection during acute type A aortic dissection is at a minimum.

Deep HCA (DHCA) has been the foundation of cerebral protection during aortic arch surgery since the reintroduction of HCA by Griepp et al in $1975 .^{9}$ Advantages offered by DHCA include bloodless aortic arch replacement and lowered systemic and cerebral cellular metabolism. However, published online

October 29, 2018
Copyright $\odot 2018$ by Thieme Medical Publishers, Inc., 333 Seventh Avenue, New York, NY 10001, USA. Tel: +1(212) 584-4662.
DOI https://doi.org/ 10.1055/s-0038-1675204. ISSN 1061-1711. 
achieving such temperatures requires extensive cooling and rewarming times. ${ }^{10}$ As a viable alternative to address concerns raised regarding DHCA, the use of moderate hypothermia $(\mathrm{MH})$ with antegrade perfusion of cerebral vessels has become increasingly popular in the past decade. $\mathrm{MH}$ has been found to reduce cardiopulmonary bypass (CPB) times, postoperative inflammation, rebleeding, and organ dysfunction. ${ }^{11}$ Although there have been extensive studies detailing the safety and efficacy of both approaches, minimal reports specifically comparing temperature selection for repair of acute type A aortic dissection exist. The purpose of this study was to compare the early clinical outcomes of $\mathrm{MH}$ versus deep hypothermia (DH).

\section{Methods}

\section{Patients}

The Society of Thoracic Surgeons Databases at the University of Iowa Hospitals and Clinics were queried to identify all patients who underwent repair of aortic dissection between January 2000 and June 2014. A total of 127 patients underwent repair for acute type A aortic dissections. Of those, 105 were repaired under $\mathrm{DH}$ and 27 were repaired under $\mathrm{MH}$. Patients with a type A dissection who did not undergo emergent surgical treatment were excluded.

A preoperative diagnosis of aortic dissection was accomplished using computed tomographic angiography, transesophageal echocardiography (TEE), or magnetic resonance imaging. The diagnosis was later confirmed at the time of operation. A database was created for entry of demographic information, procedural data, and postoperative outcomes. Dedicated data-coordinating personnel retrospectively entered the said information. Study approval from the Institutional Review Board was obtained. Consistent with the Health Insurance Portability and Accountability Act of 1996, patient confidentiality was consistently maintained.

\section{Definitions}

The Society of Thoracic Surgeons' national cardiac surgery database definitions were used for this study. Acute type A aortic dissection was defined as any dissection that involved the ascending aorta with presentation within 2 weeks of the onset of symptoms. Previous cerebrovascular accident was defined as history of central neurologic deficit persisting for more than 24 hours. Chronic renal insufficiency was defined as a serum creatinine value $>2.0 \mathrm{mg} / \mathrm{dL}$. Diabetes was defined as a history of diabetes mellitus, regardless of duration of disease or need for oral agents or insulin. Recent myocardial infarction was defined as myocardial infarction occurring within 7 days. Depressed ejection fraction was defined as ejection fraction $<40 \%$. Hemodynamic instability was defined as hypotension (systolic blood pressure $<80 \mathrm{~mm} \mathrm{Hg}$ ) or the presence of cardiac tamponade, shock, acute congestive heart failure, and myocardial ischemia and/ or infarction. Prolonged CPB time was defined as time more than the 75th percentile, which was equal to 240 minutes. Prolonged ventilatory support was defined as pulmonary insufficiency requiring ventilatory support $>24$ hours post- operatively. Postoperative stroke was defined as any new major (type I) neurologic deficit presenting in-hospital and persisting for $>72$ hours. Acute renal failure was defined as one or both of the following: (1) an increase in the serum creatinine to $>2.0 \mathrm{mg} / \mathrm{dL}$ and/or a $>$ twofold increase in the most recent preoperative creatinine level or (2) a new requirement for dialysis postoperatively. Operative mortality includes both (1) all deaths occurring during the hospitalization in which the operation was performed (even if death occurred after 30 days from the operation), and (2) those deaths occurring after discharge from the hospital, but within 30 days of the procedure.

\section{Operative Technique}

Intraoperatively, the diagnosis of type A aortic dissection was confirmed by TEE for all patients. Bilateral radial arterial lines were established. Cerebral oximetry was typically used at our institution. A median sternotomy was created to provide access. Total CPB was provided by arterial cannulation of the femoral artery or right axillary artery and venous cannulation of the right atrium. Cold blood cardioplegia administration through an antegrade approach via the ostia of the coronary arteries and/or retrograde through the coronary sinus was performed to ensure myocardial protection. The right superior pulmonary vein provided access for vent placement into the left ventricle. Restoration of the aortic root was accomplished by resection of the intimal tear followed by repair or resuspension of the aortic valve and replacement of the ascending aorta. After reaching the preferred mean cooling temperature range of 13 to $28^{\circ} \mathrm{C}$, the aortic clamp was removed and the aortic arch was examined. Antegrade cerebral perfusion was typically used in $\mathrm{MH}$ patients via the right axillary artery. Once circulatory arrest was instituted at the $\mathrm{MH}$ group, the innominate artery was clamped and antegrade perfusion was administered via the right axillary artery. Retrograde cerebral perfusion was not typically used at our institution. The distal anastomosis was then completed and antegrade aortic perfusion was established. Either a root replacement with a composite valve graft and coronary button reimplantation or a valve replacement with mechanical or tissue prosthesis was indicated for patients with irreparable damage of the aortic root or valve. Reinforcement of the proximal and distal suture lines was accomplished using Teflon (polytetrafluoroethylene) strips or, for some patients, biological glue (BioGlue surgical adhesive, Cryolife, Kennesaw, Georgia, United States).

\section{Data Analysis}

\section{Univariate Analysis}

Univariate comparisons of preoperative, operative, and postoperative variables were performed between patients repaired under $\mathrm{DH}(n=105)$ and those repaired under $\mathrm{MH}$ $(n=27)$. Normal distribution of continuous variables was assessed using the Kolmognov-Smirnov test. Continuous variables were tested using either the Student's t-test or the Mann-Whitney test, while categorical variables were assessed by the chi-square or Fisher's exact test, depending on the distribution of data. All tests were two-sided and a 
$p$-value of $\leq 0.05$ was considered statistically significant. All analyses were conducted using SPSS statistical software Version 21 (IBM Corp, Armonk, New York, United States).

\section{Results}

\section{Preoperative Characteristics}

Preoperative characteristics are summarized in - Table $\mathbf{1}$. Patients who underwent DH demonstrated higher preoperative hypertension $(p=0.004)$ and instability $(p=0.008)$. Patients in the $\mathrm{MH}$ group had higher rates of arrhythmias $(p=0.032)$ and trends toward higher levels of creatinine $(p=0.06)$. All other preoperative variables evaluated were not significantly different between the groups.

Table 1 Preoperative patient characteristics

\begin{tabular}{|l|l|l|l|}
\hline Variable $^{\text {a }}$ & $\begin{array}{l}\text { Deep } \\
(\boldsymbol{n}=105)\end{array}$ & $\begin{array}{l}\text { Moderate } \\
(\boldsymbol{n}=27)\end{array}$ & $\boldsymbol{p}$-Value \\
\hline Age, y & $62(27-86)$ & $59(35-83)$ & 0.451 \\
\hline Surgical era & & & 0.198 \\
\hline 2000-2006 & $37(35.2 \%)$ & $6(22.2 \%)$ & $\ldots$ \\
\hline 2007-2014 & $68(64.8 \%)$ & $21(77.8 \%)$ & $\ldots$ \\
\hline Diabetes & $9(8.6 \%)$ & $2(7.4 \%)$ & 0.845 \\
\hline Hypertension & $74(70.5 \%)$ & $11(40.7 \%)$ & 0.004 \\
\hline $\begin{array}{l}\text { Ejection } \\
\text { raction }\end{array}$ & $5(4.8 \%)$ & $2(7.4 \%)$ & 0.584 \\
\hline COPD & $13(12.4 \%)$ & $4(14.8 \%)$ & 0.736 \\
\hline Creatinine & $1.1(0.4-3.9)$ & $1.05(0.7-6.7)$ & 0.06 \\
\hline Female gender & $33(31.4 \%)$ & $5(18.5 \%)$ & 0.186 \\
\hline Arrhythmias & $6(5.7 \%)$ & $5(18.5 \%)$ & 0.032 \\
\hline NYHA class & & & 0.354 \\
\hline I & $6(5.7 \%)$ & $1(3.7 \%)$ & $\ldots$ \\
\hline II & $32(30.5 \%)$ & $13(48.1 \%)$ & $\ldots$ \\
\hline III & $41(39.0 \%)$ & $9(33.3 \%)$ & $\ldots$ \\
\hline $\begin{array}{l}\text { IV } \\
\text { History of cere- } \\
\text { brovascular } \\
\text { accident }\end{array}$ & $9(8.6 \%)$ & $2(7.4 \%)$ & 0.845 \\
\hline $\begin{array}{l}\text { Hemodynamic } \\
\text { instability }\end{array}$ & $29(27.6 \%)$ & $1(3.7 \%)$ & 0.008 \\
\hline $\begin{array}{l}\text { Number of } \\
\text { diseased vessels }\end{array}$ & $4(3.9 \%)$ & $1(3.7 \%)$ & $\ldots$ \\
\hline Zero & $9(4.8 \%)$ & $2(7.4 \%)$ & 0.584 \\
\hline One & $7(6.7 \%)$ & $0(0 \%)$ & $\ldots$ \\
\hline Two & $4(3.8 \%)$ & $0(0 \%)$ & $\ldots$ \\
\hline Three & & & $\ldots$ \\
\hline EF $<40$ & & & $\ldots$ \\
\hline
\end{tabular}

Abbreviations: COPD, chronic obstructive pulmonary disease; EF, ejection fraction; NYHA, New York Heart Association.

${ }^{a}$ Continuous data are shown as median (range) and categorical data are shown as percentage.

\section{Operative Characteristics}

Operative characteristics of patients repaired for acute type A aortic dissection under $\mathrm{DH}$ and $\mathrm{MH}$ are presented in - Table 2. Patients repaired under DH had higher CPB times $(p<0.001)$, a higher incidence of prolonged CPB of greater than 240 minutes $(p=0.015)$, longer circulatory arrest times $(p \leq 0.001)$, and more frequent usage of a hemiarch technique $(p=0.032)$ compared with patients repaired under $\mathrm{MH}$. Conversely, patients repaired under MH had higher systemic temperatures than those repaired under DH $(p<0.001)$. Also, cerebral protection and cannulation methods varied between the groups $(p=0.01$ and $p=0.034$, respectively) with more patients who underwent DH having retrograde cerebral perfusion and femoral cannulation compared with the patients who underwent $\mathrm{MH}$.

\section{Postoperative Characteristics}

Postoperative characteristics are depicted in -Table 3 . Incidence of stroke was higher in the DH group than in

Table 2 Operative patient characteristics

\begin{tabular}{|l|l|l|l|}
\hline Variable $^{\text {a }}$ & $\begin{array}{l}\text { Deep } \\
(\boldsymbol{n}=\mathbf{1 0 5})\end{array}$ & $\begin{array}{l}\text { Moderate } \\
(\boldsymbol{n}=\mathbf{2 7})\end{array}$ & $\boldsymbol{p}$-Value \\
\hline CPB time $>240$ min & $37(35.2 \%)$ & $3(11.1 \%)$ & 0.015 \\
\hline CPB time, min & $\begin{array}{l}219 \\
(102-535)\end{array}$ & $\begin{array}{l}173.5 \\
(89-263)\end{array}$ & $<0.001$ \\
\hline $\begin{array}{l}\text { Circulatory arrest } \\
\text { time, min }\end{array}$ & $\begin{array}{l}31.5 \\
(0-146)\end{array}$ & $\begin{array}{l}18.5 \\
(0-46)\end{array}$ & $<0.001$ \\
\hline Systemic temperature & $\begin{array}{l}18 \\
(13-23)\end{array}$ & $\begin{array}{l}26.50 \\
(24-28)\end{array}$ & $<0.001$ \\
\hline Aortic valve procedure & & & 0.749 \\
\hline Nothing & $41(39.0 \%)$ & $12(44.4 \%)$ & $\ldots$ \\
\hline Replacement & $4(3.8 \%)$ & $2(7.4 \%)$ & $\ldots$ \\
\hline Resuspension & $43(41.0 \%)$ & $10(37.0 \%)$ & $\ldots$ \\
\hline Bentall & $17(16.2 \%)$ & $3(11.1 \%)$ & $\ldots$ \\
\hline Hemiarch technique & $89(84.8 \%)$ & $18(66.7 \%)$ & 0.032 \\
\hline Total arch replacement & $7(6.7 \%)$ & $2(7.4 \%)$ & 0.892 \\
\hline Cerebral Perfusion & & & 0.01 \\
\hline No cerebral perfusion & $39(37.1 \%)$ & $13(48.1 \%)$ & $\ldots$ \\
\hline Retrograde & $28(26.7 \%)$ & $0(0 \%)$ & $\ldots$ \\
\hline Antegrade & $38(36.2 \%)$ & $14(51.9 \%)$ & $\ldots$ \\
\hline Cannulation method & & & 0.034 \\
\hline Axillary & $25(23.8 \%)$ & $13(48.1 \%)$ & $\ldots$ \\
\hline Femoral & $74(70.5 \%)$ & $12(44.4 \%)$ & $\ldots$ \\
\hline Both & $6(5.7 \%)$ & $2(7.4 \%)$ & $\ldots$ \\
\hline BioGlue/Felt strip & & & 0.028 \\
\hline BioGlue & $31(29.5 \%)$ & $13(48.1 \%)$ & $\ldots$ \\
\hline Felt strip & $25(23.8 \%)$ & $9(33.3 \%)$ & $\ldots$ \\
\hline Both & $49(46.7 \%)$ & $5(18.5 \%)$ & $\ldots$ \\
\hline
\end{tabular}

Abbreviation: CPB, cardiopulmonary bypass.

${ }^{a}$ Continuous data are shown as median (range) and categorical data are shown as percentage. 
Table 3 Postoperative complications

\begin{tabular}{|l|l|l|l|}
\hline Variable $^{\text {a }}$ & $\begin{array}{l}\text { Deep } \\
(\boldsymbol{n}=105)\end{array}$ & $\begin{array}{l}\text { Moderate } \\
(\boldsymbol{n}=27)\end{array}$ & $p$-Value \\
\hline $\begin{array}{l}\text { Deep sternal wound } \\
\text { infection }\end{array}$ & $7(6.7 \%)$ & $1(3.7 \%)$ & 0.565 \\
\hline Prolonged ventilation & $49(46.7 \%)$ & $\begin{array}{l}11 \\
(40.7 \%)\end{array}$ & 0.581 \\
\hline Acute renal failure & $19(18.1 \%)$ & $8(29.6 \%)$ & 0.185 \\
\hline Hemodialysis & $4(3.8 \%)$ & $3(11.1 \%)$ & 0.131 \\
\hline $\begin{array}{l}\text { Hemorrhage-related } \\
\text { reexploration }\end{array}$ & $11(10.5 \%)$ & $2(7.4 \%)$ & 0.633 \\
\hline Cardiac arrest & $10(9.5 \%)$ & $3(11.1 \%)$ & 0.805 \\
\hline Stroke & $13(12.4 \%)$ & $0(0 \%)$ & 0.054 \\
\hline Atrial fibrillation & $21(20.0 \%)$ & $6(22.2 \%)$ & 0.798 \\
\hline $\begin{array}{l}\text { Hospital length } \\
\text { of stay (d) }\end{array}$ & $9(0-86)$ & $8(2-24)$ & 0.25 \\
\hline Operative mortality & $18(17.1 \%)$ & $2(7.4 \%)$ & 0.208 \\
\hline
\end{tabular}

${ }^{a}$ Continuous data are shown as median (range) and categorical data are shown as percentage.

the $\mathrm{MH}$ group, but this did not reach statistical significance $(p=0.054)$.

\section{Trends over Time}

The use of $\mathrm{MH}$ increased over time from one surgical era to the next. However, this did not reach statistical significance when comparing levels of $\mathrm{DH}$ and $\mathrm{MH}$ use in the two surgical eras $(p=0.198)$.

\section{Discussion}

Our study is among the first to directly compare DH versus $\mathrm{MH}$ for cerebral protection during circulatory arrest for repair of type A aortic dissection. A previous study analyzing the German Registry for Acute Aortic Dissection Type A reported no significant differences among temperature groups in operative mortality or permanent neurological deficit when they directly compared systemic temperatures in patients with HCA as the only protective method. ${ }^{12}$ In contrast, a recent study published by Algarni et al comparing $\mathrm{DH}$ to $\mathrm{MH}$ found $\mathrm{DH}$ to be a predictor of postoperative stroke, low cardiac output syndrome, and operative mortality. ${ }^{4}$ Their findings, however, were independent of the cannulation method, cerebral protection method, and circulatory arrest time. The conflicting evidence brought from these two studies prompted our investigation with particular interest paid to cannulation, cerebral protection, and circulatory arrest time.

\section{Principal Findings}

In our study, the overall operative mortality was $15.1 \%$, which compares with the bottom end of recent studies. ${ }^{1-5}$ Operative mortality in our DH cohort (17.1\%) demonstrated greater than twofold increase over that of our $\mathrm{MH}$ cohort (7.4\%). Likewise, the prevalence of stroke was much higher using $\mathrm{DH}$ over using $\mathrm{MH}$ (12.4\% vs. $0 \%$ ).

$\mathrm{DH}$ without a cerebral perfusion adjunct during aortic surgery has been a proven method of protection with operative mortality rates as low as $6.3 \%$ and stroke rates from 3.1 to $8 \%$, but these findings are limited to circulatory arrest times below 40 minutes. $^{13,14}$ Potential drawbacks with $\mathrm{DH}$ in comparison to $\mathrm{MH}$ may be the cause of the increased risks for morbidity and mortality that our study and others have demonstrated. Autoregulation of cerebral blood flow markedly diminishes with decreasing temperature and nearly absolves at $12^{\circ} \mathrm{C}^{10}$ This effect uncouples cerebral blood flow, for example, from metabolism starting at roughly $22^{\circ} \mathrm{C}$ and creates an overprovision of blood. ${ }^{15}$ Afterwards, extended rewarming periods associated with $\mathrm{DH}$ create a secondary vasodilation leading to edema, and the prolonged acidosis in the brain tissue causes reperfusion injury. ${ }^{16,17}$ Further, a study by Strauch et al demonstrated that effective reduction in oxygen consumption within brain cells takes place at $28^{\circ} \mathrm{C}$ and does not improve with increasingly lower temperatures, which calls into question the metabolic benefits of DHCA. ${ }^{18}$

Perhaps the strongest negative effect of $\mathrm{DH}$ originates from increased CPB times and subsequent length of operation in comparison with $\mathrm{MH} .{ }^{7,19}$ Extended CPB times during cardiac surgery are implicated in increased risk of acute renal insufficiency, stroke, and mortality. ${ }^{20-22}$ These effects can be compounded based on the condition of the patient. Diminished hematocrit and glycemic levels can increase perioperative risk during the use of $\mathrm{CPB} .{ }^{23,24}$ In our study, the median CPB time was 219 minutes for the DH group and 173.5 minutes for the MH group $(p<0.001)$. Also, the number of patients reaching the extended CPB time of 240 minutes in the DH group tripled than that of the $\mathrm{MH}$ group $(p<0.015)$. An increased prevalence of postoperative risk found using $\mathrm{DH}$ might actually arise secondary to increased $\mathrm{CPB}$ times.

\section{Trends in DH versus MH Selection over Time}

At our institution, $\mathrm{MH}$ has only recently become heavily used. A trend for its use is demonstrated by the 21 cases in the 2007 to 2014 surgical era in comparison to the 6 completed in the 2000 to 2006 surgical era $(p=0.198)$. This is further established by the fact that 17 of the $21 \mathrm{MH}$ cases were completed within the past 3 years.

This trend seems to have emerged due to the use of antegrade cerebral perfusion and growing evidence advocating for increased safety and efficacy with $\mathrm{MH}$. DH was no longer necessary with the increased use of antegrade cerebral perfusion. A recent study by Comas et al reported that the use of $\mathrm{MH}$ and selective antegrade cerebral perfusion in acute type A aortic dissection cases significantly decreased $\mathrm{CPB}$ times, operative mortality, incidence of renal failure, incidence of tracheostomy, and length of hospital stay compared with patients undergoing non-MH with the same selective antegrade cerebral perfusion. ${ }^{25}$ Leshnower et al continued one step further and stratified temperatures in the traditional $\mathrm{MH}$ range for elective hemiarch replacement. 
They found mild hypothermia $\left(>28^{\circ} \mathrm{C}\right.$ ) to significantly reduce the incidence of permanent neurological deficits over $\mathrm{MH}\left(24-28^{\circ} \mathrm{C}\right)$ suggesting improved cerebral protection with warmer temperatures ( $2.5 \%$ vs. $7.2 \%, p=0.01) .{ }^{26}$ Our study demonstrated similar decreases in stroke prevalence for $\mathrm{MH}$ over $\mathrm{DH}$, although our study did not reach statistical significance (0\% vs. $12.4 \%, p=0.054) .{ }^{27}$

\section{Clinical Implications}

We conducted an observational study to assess the impact of HCA temperature selection on short- and long-term outcomes following repair of acute type A aortic dissection. In this study, we examined an unselected cohort of patients from a single academic institution. This study is among only a few to directly compare use of DH and MH in surgery of acute type A aortic dissections. Temperature selection affected early clinical outcomes following acute type A aortic dissection repair in our analysis. With $\mathrm{MH}$, operative mortality and stroke decreased, and late survival improved. Also, СРB times were dramatically and expectedly reduced in our MH group. Based on the results of our study, the use of $\mathrm{MH}$ is recommended, especially with evidence that shorter CPB times are associated with better outcomes. However, further studies are needed to identify patient characteristics that might merit the use of one cerebral protection strategy over the other.

\section{Study Limitations}

The lack of power in our study due to the relatively small sample size in the MH group limited the confidence in our findings and precluded multivariable analysis. To this end, potential preoperative confounding factors such as hemodynamic instability and hypertension could not be fully explored. Further study of reoperations on the remaining dissected aorta, the causes of late mortality, and the fate of the false lumen were outside the scope of our analysis. In future, these should be foci for evaluating long-term outcomes of acute type A aortic dissection repair. Our report represents a single institution experience with a limited amount of repairs of type A dissection per year ( 10/year). Our institution is a tertiary referral center that accepts patients referred by our institution without the expertise to treat this complex disease. Furthermore, in our study axillary and femoral cannulation varied significantly between the $\mathrm{MH}$ and $\mathrm{DH}$ groups and thus the higher risk of stroke in the DH group may be related to the higher rate of femoral cannulation in that group. However, we previously reported no differences in stroke risk between the two approaches. $^{28}$

\section{Conclusions}

Moderate hypothermia is an effective alternative to for surgical repair of acute type A aortic dissection and appears to have protective benefits.

\section{Funding}

None.

\section{References}

1 Tsai TT, Trimarchi S, Nienaber CA. Acute aortic dissection: perspectives from the International Registry of Acute Aortic Dissection (IRAD). Eur J Vasc Endovasc Surg 2009;37(02):149-159

2 Weigang E, Conzelmann LO, Kallenbach K, Dapunt O, Karck M. German registry for acute aortic dissection type A (GERAADA)lessons learned from the registry. Thorac Cardiovasc Surg 2010; 58(03):154-158

3 Wiedemann D, Kocher A, Dorfmeister M, et al. Effect of cerebral protection strategy on outcome of patients with Stanford type A aortic dissection. J Thorac Cardiovasc Surg 2013;146(03):647-655

4 Algarni KD, Yanagawa B, Rao V, Yau TM. Profound hypothermia compared with moderate hypothermia in repair of acute type $A$ aortic dissection. J Thorac Cardiovasc Surg 2014;148(06): 2888-2894

5 Tolenaar JL, van Bogerijen GH, Eagle KA, Trimarchi S. Update in the management of aortic dissection. Curr Treat Options Cardiovasc Med 2013;15(02):200-213

6 Usui A, Miyata H, Ueda Y, Motomura N, Takamoto S. Risk-adjusted and case-matched comparative study between antegrade and retrograde cerebral perfusion during aortic arch surgery: based on the Japan Adult Cardiovascular Surgery Database : the Japan Cardiovascular Surgery Database Organization. Gen Thorac Cardiovasc Surg 2012;60(03):132-139

7 Ueda Y. What is the best method for brain protection in surgery of the aortic arch? Retrograde cerebral perfusion. Cardiol Clin 2010; 28(02):371-379

8 Czerny M, Fleck T, Zimpfer D, et al. Risk factors of mortality and permanent neurologic injury in patients undergoing ascending aortic and arch repair. J Thorac Cardiovasc Surg 2003;126(05): 1296-1301

9 Griepp RB, Stinson EB, Hollingsworth JF, Buehler D. Prosthetic replacement of the aortic arch. J Thorac Cardiovasc Surg 1975;70 (06):1051-1063

10 Bachet J. What is the best method for brain protection in surgery of the aortic arch? Selective antegrade cerebral perfusion. Cardiol Clin 2010;28(02):389-401

11 Kamiya H, Hagl C, Kropivnitskaya I, et al. The safety of moderate hypothermic lower body circulatory arrest with selective cerebral perfusion: a propensity score analysis. J Thorac Cardiovasc Surg 2007;133(02):501-509

12 Krüger T, Weigang E, Hoffmann I, Blettner M, Aebert H; GERAADA Investigators. Cerebral protection during surgery for acute aortic dissection type A: results of the German Registry for Acute Aortic Dissection Type A (GERAADA). Circulation 2011;124(04): 434-443

13 Gega A, Rizzo JA, Johnson MH, Tranquilli M, Farkas EA, Elefteriades JA. Straight deep hypothermic arrest: experience in 394 patients supports its effectiveness as a sole means of brain preservation. Ann Thorac Surg 2007;84(03):759-766, discussion 766-767

14 Percy A, Widman S, Rizzo JA, Tranquilli M, Elefteriades JA. Deep hypothermic circulatory arrest in patients with high cognitive needs: full preservation of cognitive abilities. Ann Thorac Surg 2009;87(01):117-123

15 Harrington DK, Fragomeni F, Bonser RS. Cerebral perfusion. Ann Thorac Surg 2007;83(02):S799-S804, discussion S824-S831

16 Kamler M, Goedeke J, Pizanis N, Milekhin V, Schade F-U, Jakob H. In vivo effects of hypothermia on the microcirculation during extracorporeal circulation. Eur J Cardiothorac Surg 2005;28(02): 259-265

17 Hagl C, Khaladj N, Peterss S, et al. Hypothermic circulatory arrest with and without cold selective antegrade cerebral perfusion: impact on neurological recovery and tissue metabolism in an acute porcine model. Eur J Cardiothorac Surg 2004;26(01): 73-80

18 Strauch JT, Spielvogel D, Haldenwang PL, et al. Impact of hypothermic selective cerebral perfusion compared with hypothermic 
cardiopulmonary bypass on cerebral hemodynamics and metabolism. Eur J Cardiothorac Surg 2003;24(05):807-816

19 Bakhtiary F, Dogan S, Zierer A, et al. Antegrade cerebral perfusion for acute type A aortic dissection in 120 consecutive patients. Ann Thorac Surg 2008;85(02):465-469

20 Kumar AB, Walker C, Kim E, Suneja M. Time on cardiopulmonary bypass and risk of postoperative acute kidney injury: 12AP2-4. Eur J Anaesthesiol 2012;29:178(EJA)

21 McKhann GM, Goldsborough MA, Borowicz LM Jr, et al. Predictors of stroke risk in coronary artery bypass patients. Ann Thorac Surg 1997;63(02):516-521

22 Halkos ME, Kerendi F, Myung R, Kilgo P, Puskas JD, Chen EP. Selective antegrade cerebral perfusion via right axillary artery cannulation reduces morbidity and mortality after proximal aortic surgery. J Thorac Cardiovasc Surg 2009;138(05): 1081-1089

23 Doenst T, Wijeysundera D, Karkouti K, et al. Hyperglycemia during cardiopulmonary bypass is an independent risk factor for mortality in patients undergoing cardiac surgery. J Thorac Cardiovasc Surg 2005;130(04):1144.e1
24 Karkouti K, Djaiani G, Borger MA, et al. Low hematocrit during cardiopulmonary bypass is associated with increased risk of perioperative stroke in cardiac surgery. Ann Thorac Surg 2005; 80(04):1381-1387

25 Comas GM, Leshnower BG, Halkos ME, et al. Acute type a dissection: impact of antegrade cerebral perfusion under moderate hypothermia. Ann Thorac Surg 2013;96(06):2135-2141

26 Leshnower BG, Myung RJ, Thourani VH, et al. Hemiarch replacement at $28^{\circ} \mathrm{C}$ : an analysis of mild and moderate hypothermia in 500 patients. Ann Thorac Surg 2012;93(06):1910-1915, discussion 1915-1916

27 Tsai TT, Evangelista A, Nienaber CA, et al; International Registry of Acute Aortic Dissection (IRAD). Long-term survival in patients presenting with type A acute aortic dissection: insights from the International Registry of Acute Aortic Dissection (IRAD). Circulation 2006;114(1, Suppl):I350-I356

28 Stamou SC, Gartner D, Kouchoukos NT, et al. Axillary versus femoral arterial cannulation during repair of type A aortic dissection?: an old problem seeking new solutions Aorta (Stamford) 2016;4(04):115-123 